\title{
A NOVA SISTEMÁTICA DO IMPOSTO SOBRE OPERAÇÕES DE MERCADORIAS E SERVIÇOS
}

\section{ARTIGO ORIGINAL}

\author{
LUZ, Bruno Rogério Soares $\mathrm{Da}^{1}$
}

LUZ, Bruno Rogério Soares Da. A nova sistemática do imposto sobre operações de mercadorias e serviços. Revista Científica Multidisciplinar Núcleo do Conhecimento. Ano. 06, Ed. 12, Vol. 05, pp. 99-114. Dezembro de 2021. ISSN: 24480959, Link de

acesso: https://www.nucleodoconhecimento.com.br/contabilidade/sistematica-doimposto

\section{RESUMO}

O Imposto sobre Circulação de Mercadorias e Serviços (ICMS), é um imposto de competência estadual e do distrito federal. Ele é cobrado em todas as operações de consumo no Brasil, na origem da venda da mercadoria. Esse imposto acaba de passar por uma mudança em sua sistemática de recolhimento, antes o ICMS era recolhido no estado onde a empresa que vende o produto está alocada, o que muitas vezes gerava perda de arrecadação e aumento de divergência entre os estados menos favorecidos. Portanto, se fez necessário rever esta sistemática. Diante disto, o presente artigo, tem como questão norteadora: como a nova forma de tributar o ICMS pode contribuir para minimizar as divergências existentes na economia entre os estados? O objetivo geral é investigar e esclarecer a nova sistemática do imposto sobre operações de mercadorias e serviços através da EC 87/2015. Deste modo, o presente artigo destaca a importância da nova sistemática de recolhimento do imposto nos estados brasileiros, qualificando os contabilistas, contribuintes, consumidores, visando a justiça tributária de forma a minimizar as baixas causadas pela guerra fiscal

\footnotetext{
${ }^{1}$ Graduado em bacharelado em ciências contábeis pela universidade estadual do piauí - uespi; pós-graduado em mba em auditoria e controladoria - faculdades integradas do rio grande do norte.
} 
no Brasil. Como metodologia, realizou-se uma pesquisa bibliográfica sobre a temática. A pesquisa demostra, através do princípio da tributação no destino, ou seja, através da receita sendo recolhida e arrecadada pela unidade da federação, aos quais os produtos se destinam e não onde são produzidos, a constatação de avanços e potenciais de incremento na arrecadação dos estados menos favorecidos, tornando justas as operações.

Palavras-Chave: Imposto sobre Circulação de Mercadorias e Serviços, Recolhimento, Sistema Tributário, Guerra Fiscal.

\section{INTRODUÇÃO}

O Imposto sobre Circulação de Mercadorias e Serviços (ICMS) é um imposto de competência estadual que incide sobre operações relativas à circulação de mercadorias e sobre prestações de serviços de transporte interestadual e intermunicipal e de comunicação, que abordam sobre a Constituição da República Federativa no seu art. 155, do inciso II, $\S \S 2^{\circ}$ e $3^{\circ}$, e a Lei Complementar $n^{\circ} 87$, de 13 de setembro de 1996, Brasil (1996).

A fim de contextualizar a presente pesquisa sobre o ICMS, a arrecadação per capita de dois estados do nordeste como Maranhão e Piauí, dizem respeito somente a $25 \%$ e 31\% da média brasileira, ainda sendo uma situação amenizada, porém não resolvida, logo em seguida às transferências diretas da União os recursos subiram para 54\% no Maranhão e 66\% no Piauí, Paes (2009).

Essa situação entre os estados ainda é desfavorável a elas, pois em relação à disponibilidade financeira de alguns estados, que provém de uma aquisição do princípio da origem na tributação do ICMS nas transações interestaduais. Em decorrência a este fato, uma pequena parte da arrecadação deste fim lucrativo se destina ao Estado que produz mercadoria. Assim, o ICMS deixa de ter caráter de imposto sobre o consumo, transformando-se em um tributo mesclado, incidindo tanto sobre a produção quanto o consumo, Paes (2009). 
Com isso, propõe-se aqui analisar os efeitos da economia sobre as arrecadações referentes aos estados brasileiros, desde a adoção até o destino de tal, no qual o ICMS é empregado totalmente aos estados, em que a mercadoria é consumida e voltada em imposto na condição de tributo sobre o consumo. Essa mudança deve promover a redistribuição de recursos, levando algumas vantagens para os estados consumidores.

É por tal motivo que a dinâmica do princípio do destino sempre se manteve como um importante motivo para ser implantada a reforma Tributária, mesmo que os estados que produzem se contrapõem, por medo da perca de receitas. Assim, nos últimos anos, os estados conseguiram, com a arrecadação do ICMS mais de $80 \%$ do seu peso, Serra (1999).

A partir da leitura de materiais, podemos destacar que, diante das escritas de cunho nacional, existem poucos trabalhos que versam sobre o impacto da mudança da sistemática do ICMS. Quem deu os primeiros passos, elaborando trabalhos nessa área, falando da redistribuição de receitas referentes a adoção do princípio do destino, mesmo com pouco embasamento, foi Varsano (1997), mas foi o trabalho de Paes e Siqueira (2005) que adotou um modelo mais consolidado, no qual calculou perdas e ganhos para os Estados, com mais clareza e embasamento. O seu artigo focou com profundidade na demanda alterando os resultados obtidos por aqueles autores.

Segundo Yamao (2014), o ICMS - imposto estadual incidente sobre as operações relativas à circulação de mercadorias e sobre a prestação de serviços de transporte interestadual e intermunicipal e de comunicações - é, sem dúvida, o imposto com a maior arrecadação no país, além de ser a principal fonte de receita dos Estados e do Distrito Federal, recebendo da Carta Magna/1988 mais extenso tratamento constitucional.

O profissional de contabilidade precisa estar a pá dos desafios que vierem a acontecer e, para isso, é necessário se esforçar para que a evolução aconteça no sentido dos conhecimentos específicos, gerais e até emocionais, a fim de evoluírem na geração 
de informação, negociação, capacidade de inovação e visão de futuro, além da progressão de habilidades e conhecimentos técnicos.

Assim, a correta aplicação desta sistemática proporciona incremento na arrecadação dos estados, que consequentemente eleva os investimentos em educação, saúde, segurança, e demais projetos de ordem social que perdiam investimentos devido a disputa fiscal.

Deste modo, a pesquisa destaca a importância da nova sistemática de recolhimento do ICMS para os estados brasileiros, qualificando os contabilistas, contribuintes, consumidores e assim buscar a justiça tributária de forma a contribuir para a promoção de dias melhores a todos.

Com o advento do ajuste fiscal, evolução tecnológica e da repercussão da economia mundial, expressões como planejamento e diagnóstico empresarial, marketing, comunicação, capacitação dos profissionais, se configuram como elementos obrigatórios a serem analisados por todos os segmentos profissionais nos dias de hoje, Mari (2006).

Logo, a escolha pelo tema "A nova sistemática do imposto sobre operações de mercadorias e serviços", deu-se em virtude de sua grande relevância social, sobretudo, pelo fato da Contabilidade ter um importante papel no auxílio à tomada de decisões. Diante disso, é importante conhecer e esclarecer todos os aspectos dessa nova forma de recolhimento.

Portanto, com esse trabalho, além de mostrar a sua possibilidade de execução com os recursos disponíveis, contribui também para o conhecimento já existente acerca do tema, bem como para a sociedade de maneira geral ou específica.

Neste contexto, tem como questão norteadora: como a nova forma de tributar o ICMS pode contribuir para minimizar as divergências existentes na economia entre os estados? 
O objetivo geral é investigar e esclarecer a nova sistemática do imposto sobre operações de mercadorias e serviços através da EC 87/2015 e de forma especifica, busca-se: apresentar, de forma objetiva, algumas das situações vinculadas à nova sistemática de recolhimento do Imposto sobre Circulação de Mercadorias e Serviços (ICMS), identificar as possibilidades de ganho com a nova sistemática de recolhimento do ICMS, destacar a nova sistemática de recolhimento do ICMS, como instrumento de orientação na divisão das alíquotas do ICMS, entre os estados.

O trabalho em questão trata-se de uma pesquisa bibliográfica, baseado em pesquisas já desenvolvidas na área contábil, em relação à nova sistemática do ICMS, a fim de desenvolver a pesquisa com mais ênfase, foram realizadas leituras de diversos materiais como artigos, revistas e outros meios eletrônicos.

Para o levantamento deste trabalho as pesquisas levaram em consideração os seguintes passos metodológicos: levantamento bibliográfico sobre a temática sugerida para a pesquisa a partir do arquivo pessoal de artigos inseridos na base de dados da Scielo, contribuindo para o aprofundamento do conhecimento do tema investigado, permitindo também, a síntese de múltiplos estudos publicados e possibilita conclusões gerais a respeito de uma particular área em estudo (MENDES; SILVEIRA; GALVÃO, 2008).

Segundo Marconi e Lakatos (2009), as pesquisas não se iniciam sem algum embasamento teórico, o pesquisador precisa, inicialmente, realizar leituras, conhecer a temática abordada e buscar fontes bibliográficas seguras para o seu desenvolver. Toda a escrita teórica teve embasamento teórico, a partir de autores que versam sobre 0 assunto.

Esse tipo de pesquisa inclui a análise de estudos relevantes que dão suporte para a tomada de decisão e a melhoria da prática, permitindo a síntese do estado do conhecimento de um determinado assunto, além de apontar lacunas do conhecimento que precisam ser preenchidas com a realização de novos estudos (MENDES; SILVEIRA; GALVÃO, 2008). 
A Revisão de Literatura tem por objetivo conhecer variados apoios científicos destinados a um determinado tema. Além disso, é oferecido um suporte total às fases de todos os tipos de pesquisa, auxiliam ainda a definir o problema em questão, determinando os seus objetivos, no desenvolver das hipóteses, fundamentação teórica, justificativa e elaboração do relatório final.

Um dos traços que marcam a federação brasileira é a desigualdade regional. Conseguir ir além dessa desigualdade é um desafio enorme e se alia a características econômicas, sociais e culturais. Logo, é importante destacar como a nova forma de tributar o ICMS pode contribuir para minimizar essas desigualdades existentes na economia entre os entes da federação.

\section{REFERENCIAL TEÓRICO}

\subsection{NOVA SISTEMÁTICA DE RECOLHIMENTO DO ICMS}

A partir do ano de 2016, foi implantada a nova sistemática do recolhimento do ICMS interestadual, a modificação foi realizada através da emenda 87/2015 da Constituição Federal, Brasil (2015).

A partir da alteração, houve a necessidade do recolhimento diferencial entre a porcentagem interestadual de $4 \%, 7 \%$ e $12 \%$ com relação às porcentagens anteriores de destino, Assolari (2015). Além disso,

\footnotetext{
A Emenda Constitucional dispôs ainda sobre a responsabilidade pelo recolhimento do imposto que ficará a cargo do destinatário, quando esse for contribuinte do imposto; e ao remetente, quando o destinatário não for contribuinte do imposto; conforme previsto no art. $1^{\circ}$, incisos VII e VIII do $\S 2^{\circ}$ do art. 155 da Constituição Federal (BRASIL, 1988).
}

A nova regra de recolhimento do ICMS começou a vigorar em de janeiro de 2016. Assim sendo, foi aplicada de maneira sucessiva todos os anos. É essencial perceber que tal mudança afetou todos os contribuintes que fazem operações com outros estados e não tal somente as empresas de E-commerce e/ou vendas pela internet, Zanocchi (2016). 
Assim, constata-se que as novas regras destinadas ao ICMS foram: as empresas de porte simples também poderão recolher o imposto; o diferencial de alíquota será orçamentado sobre as operações para venda ao consumidor final e contribuinte, além disso a total responsabilidade do recolhimento do referido imposto começou a ser atribuída ao destinatário e ao remetente, se estes forem contribuintes com o imposto, Brasil (1988). Em caso de servidores destinados a transportes, estes devem confirmar junto ao estado que tenham prestação de serviço na área.

Caso a empresa tenha grandes movimentações em outros estados destinados ao consumidor final não contribuinte, é aconselhado que seja feita uma inscrição de substituto tributário nos estados de destino, possibilitando o pagamento através da apuração mensal, ou seja, será pago em uma única guia, este cadastro será efetuado de forma simplificada de acordo com a Cláusula terceira do Convênio ICMS 152 de 2015 (RECOLHIMENTO DO DIFERENCIAL DE ALÍQUOTA, 2015).

Assim, modificou-se então a sistemática de recolhimento do ICMS, portanto, as empresas deverão ter a informação sobre os seus clientes e consumidores, a fim de deliberar responsabilidades sobre o recolhimento do ICMS, além disso é necessário ter uma conexão maior com o profissional de contabilidade para que este esteja atualizado sobre as alíquotas internas dos estados distintos.

A nova sistemática do ICMS veio a impactar o destino das empresas e suas vendas, que passaram a optar pelo simples nacional, como por exemplo:

Antes de 2016: 1- Gerar a nota fiscal eletrônica. 2- Imprimir duas vias da nota fiscal. 3- Adicionar uma via junto ao produto. 4- Enviar o produto. 5- Pagar a guia do imposto SIMPLES no final do mês. Em 2016: 1- Gerar a nota fiscal eletrônica. 2- Imprimir duas vias da nota fiscal. 3- Checar a tabela de alíquota de ICMS, de acordo com o seu estado e o do cliente. 4- Calcular a diferença da alíquota interna e a alíquota interestadual entre os dois estados. No caso de uma venda do RS ao RJ, a alíquota interna é de $19 \%$ e a interestadual é de $12 \%$. Ou seja, o valor da diferença de ICMS é de 7\%. 5- Dividir esta diferença de $7 \%$ em duas partes: $40 \%$ dela fica para o estado do cliente e $60 \%$ para o nosso. 6- Entrar no site da Secretaria da Fazenda (SEFAZ) e emitir a guia para pagamento dos $40 \%$ dos $7 \%$ que vai para o estado do RJ. Este site varia de acordo com o estado do cliente e os campos a serem digitados também mudam. Digitar as informações da sua empresa e da venda manualmente para emitir o Guia Nacional de Tributos Interestaduais (GNRE). 7- Imprimir a guia do GNRE. 8- Pagar a guia do GNRE. 9- Imprimir o comprovante de pagamento do GNRE. 
10- Juntar a nota fiscal, a GNRE emitida e paga, assim como o comprovante de pagamento e coloque-os junto ao produto. 11- Enviar o produto ao cliente. 12- Pagar a guia do imposto SIMPLES no final do mês (GAEL, 2016, p. 1).

De acordo com Gael (2018), as alterações do convênio ICMS 93/2015 trouxeram novas regras para a aplicação, assim as vendas que se destinam ao consumidor final que não contribui com o ICMS e que se localiza em outra região do país não fazem parte deste novo sistema.

A partir de $1^{\circ}$ de janeiro de 2016 foi aplicada uma série de mudanças no recolhimento do ICMS em uma sistemática interestadual para prestações de serviços e mercadorias àqueles que não contribuem com o ICMS. Assim, pode-se concretizar que devido a mudança de alíquotas, gerador a partir de acordo com os novos critérios estabelecidos pelo Convênio ICMS 93/2015 do Conselho Nacional de Política Fazendária (Confaz). A decisão do Confaz é desdobramento da conhecida como "Pec dos eletrônicos" que alterou a sistemática de recolhimento do tributo, determinando que a responsabilidade pelo recolhimento do imposto correspondente à diferença entre a alíquota interna e a interestadual será atribuída totalmente ao destinatário até 2019, Gael (2016).

Em recorrência às novas medidas adotadas pelo ICMS 93/2015, foi possível ter algumas alterações nos impostos e operações interestaduais.

De acordo com a base do Ministério da Fazenda (2017), em 2016 foi recolhido 60\% pela unidade da federação de origem e $40 \%$ para o destino, em 2017 foi recolhido $40 \%$ na origem e $60 \%$ no destino; e para finalizar, em 2018 , foram $20 \%$ da origem e $80 \%$ para o destino.

Logo, a nova sistemática ocorrerá de formar gradativa até que em 2019 o UF de destino passou a recolher $100 \%$ do tributo, se concretizando o estabelecido pelo princípio do destino na tributação. Mais uma vez, as mudanças buscaram amenizar a disputa entre estados, a famosa "guerra fiscal". 


\subsection{A GUERRA FISCAL}

Segundo Arbix (2000), a Guerra Fiscal se conceitua como uma disputa entre lugares diversos a fim de atrair e aproximar investimentos, empresas e indústrias. Tudo isso se dá pelo fato de questões socioespacial. Quando a disputa se torna maior e exagerada, ocorre maiores problemas não havendo uma comunicação regular, sendo ela desmedida.

Figura 1: Charge crítica de Edgar Vasques à Guerra Fiscal no Brasil

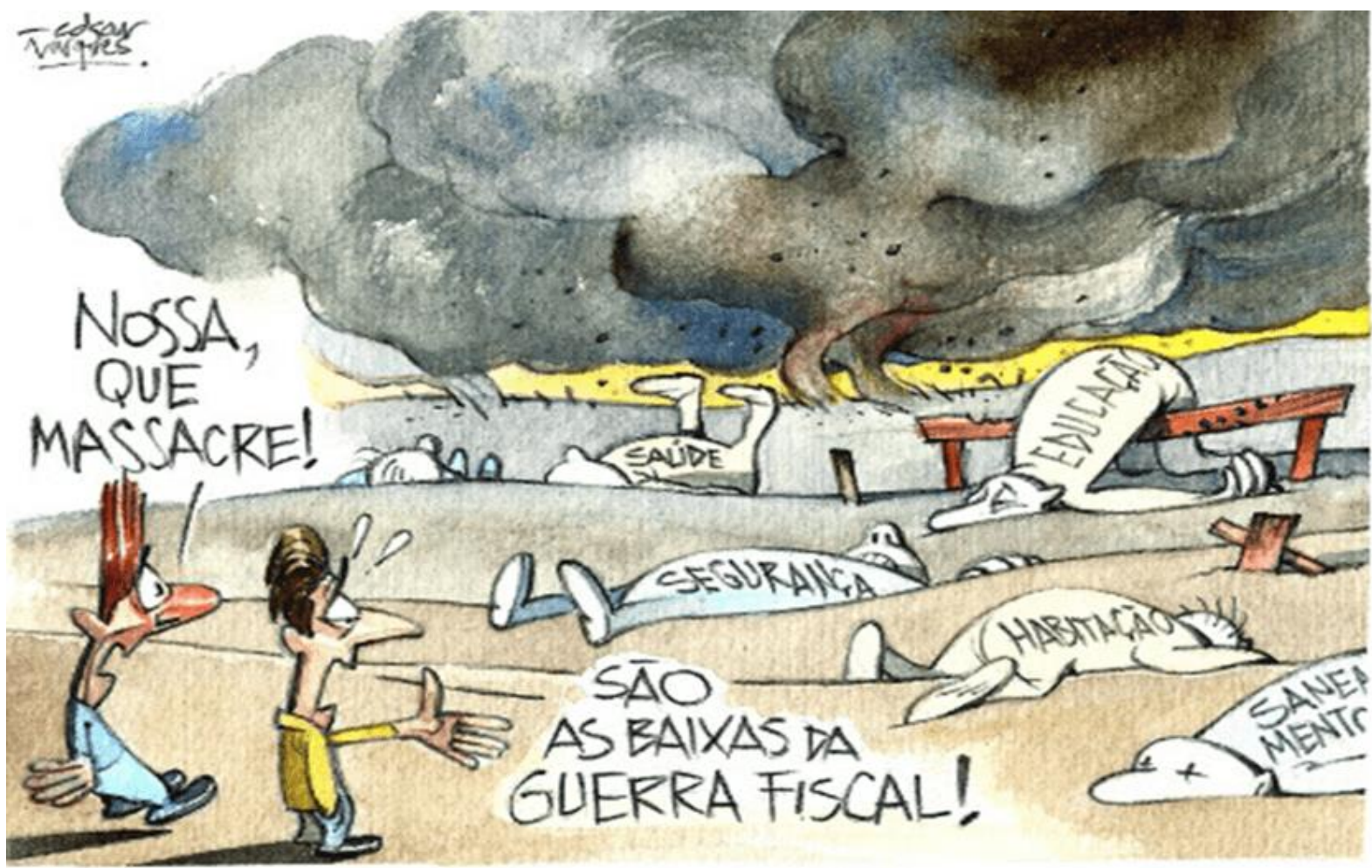

Fonte: PENA, Rodolfo F. Alves. Guerra Fiscal no Brasil. Brasil Escola.

É importante entender os motivos pelos quais ocasionaram a guerra fiscal no nosso país, portanto foram três motivos:

a)a liberdade dos estados da União em regular a sua própria política fiscal, sobretudo referente à cobrança do Imposto sobre Circulação de Mercadorias e Serviços - ICMS. Esse imposto, além de outras cobranças e taxas, passou a ser reduzido ou até isento por um período determinado para garantir que grandes empresas ou indústrias deslocassem-se para um dado local para gerar empregos. 
b)o processo histórico de concentração dos investimentos e das indústriasem algumas poucas áreas regionais do país. Com isso, as regiões mais carentes de investimentos e até de infraestrutura para gerar empregos e arrecadação passaram a "apelar" por medidas algumas até inconstitucionais - para atrair empresas e capitais.

c)a abertura econômicae a busca pelo máximo investimento de grupos estrangeiros no país, o que gerou uma maior competição entre os lugares para o recebimento desses investimentos (PENA, 2021, p. 1).

Com isso, pode-se destacar que esses foram os principais motivos, mas que não foram os únicos que ocasionam para se intensificar a Guerra Fiscal no Brasil. Grandes empresas criaram mais expectativas de crescer os lucros e diminuir os custos, além de optarem por lugares que tenham rápida produção e transporte e menor carga de impostos.

Quando um valor em alta é deixado de ser repassado para o poder público o problema se torna maior, no qual as unidades federativas do país não conseguem equilíbrio de suas contas. O poder público em muitos casos tende a reduzir os investimentos em setores da sociedade, como é o caso da educação e saúde. Com isso, nota-se que a diminuição dos investimentos públicos é uma das principais consequências da Guerra Fiscal.

A Emenda Constitucional no 87/2015 concedeu uma nova capacidade tributária aos Estados, no que diz respeito ao Imposto sobre Operações atinentes à Circulação de Mercadorias, de Transportes Interestadual e Intermunicipal e de Comunicação (ICMS).

Isto porque, as redações anteriores dos incisos VII e VIII do referido $\S$ $2^{\circ}$ previam a incidência do imposto relativo à diferença entre as alíquotas interna e interestadual nas operações e prestações que destinem mercadorias e serviços a consumidor final, contribuinte do ICMS, localizado em outro Estado e, após as alterações promovidas pela $E C$ no 87/2015, o imposto referente a esta diferença também será devido nas operações prestações interestaduais destinadas a consumidor final não contribuinte (ICMS, 2017).

Foi editado então o convênio ICMS no 93/2015 pelos estados e o Distrito Federal, que logo em seguida foi alterado pelo convênio ICMS n 152/2015, que buscava unir os procedimentos que iriam ser observados de acordo com as operações e prestações 
se serviços interestaduais, que visavam direcionar mercadorias e serviços ao consumidor final que não contribuísse dentro do ICMS.

Propõe-se então, na segunda cláusula do convênio ICMS 93/2015, que o prestador do serviço ou remetente do bem deve utilizar alíquota interna prevista na unidade de destino para o cálculo do ICMS. Além disso, deve-se aplicar a alíquota entre os estados e por fim calcular o imposto e o estado de origem recolher.

Pode-se observar, de acordo com (DATA INFO, 2016), o adicional de alíquota do $\S 1^{\circ}$ do art. 82 do ADCT tem como objetivo financiar o Fundo de Erradicação da Miséria (FEM), além disso, se aplicam às operações interestaduais que se propõe a destinar os bens e mercadorias ao consumidor final, que independente da contribuição se localiza no estado de origem do imposto correspondente.

\subsection{A EC 87/2015}

Com a mudança da sistemática é necessário um recolhimento diferencial de alíquota e alíquota em nível interestadual, nas seguintes porcentagens: 4\%, $7 \%$ e $12 \%$, diferenciando-se com a alíquota interna do estado em que se destina, o recolhimento do imposto será atribuído da seguinte forma:

1. Ao destinatário, quando esse for contribuinte do imposto;

2. Ao remetente, quando o destinatário não for contribuinte do imposto.

A nova regra passou a vigorar no ano de 2016 e será aplicada de forma gradativa anualmente conforme os prazos estabelecidos na tabela a seguir. As proporções indicadas referem-se ao valor que seria devido a título de diferencial de alíquotas.

Tabela 1: partilha do tributo entre UF de origem e da UF destinatária do consumidor final

Ano

\% partilha do tributo entre UF de origem e da UF destinatária do consumidor final

\begin{tabular}{l|l} 
UF Origem & UF destino
\end{tabular} 


\begin{tabular}{|l|l|l|}
\hline $2015^{\star}$ & $80 \%^{*}$ & $20 \%^{*}$ \\
\hline 2016 & $60 \%$ & $40 \%$ \\
\hline 2017 & $40 \%$ & $60 \%$ \\
\hline 2018 & $20 \%$ & $80 \%$ \\
\hline A partir de 2019 & - & $100 \%$ \\
\hline
\end{tabular}

Fonte: Portal Tributário - ICMS (2015)

Em 2015 pode-se observar que foi inofensiva a aplicação destes percentuais, no entanto, o art. $3^{\circ}$ da Emenda em questão propõe que ela tende a surtir efeitos no ano seguinte e depois de 90 (noventa) dias desta, ou seja, a partir de 2016.

Além disso, é importante frisar que a mudança pode afetar todos os contribuintes do ICMS, desde aqueles que desejam realizar operações interestaduais, não contando somente com empresas de E-commerce, além daqueles que praticam vendas pela interne, como se pode perceber aos longos dos últimos anos. Portanto,

O Imposto sobre a Circulação de Mercadorias e Serviços, de competência estadual, tem como principal característica a nãocumulatividade, isto é, a cada operação é compensado o montante do imposto calculado nas etapas anteriores. Pode ser seletivo, em função da essencialidade dos bens tributados, fixando alíquotas menores para gêneros de primeira necessidade e é o imposto com maior capacidade de arrecadação no Sistema Tributário Brasileiro (MASSARDI, 2014, p. 153).

O autor coloca que, em períodos anteriores CF 88 era destinado apenas $20 \%$ da arrecadação do ICMS aos municípios e para os Estados, $80 \%$. Com a nova sistemática, aumentou-se então 05\% para cada município sobre a arrecadação.

Com relação à distribuição da Quota-parte do ICMS, a CF 88 propõe que $75 \%$ dos recursos fossem rateados proporcionalmente aos municípios e os outros $25 \%$ distribuídos de acordo com a lei estadual.

Nesse sentido, pontua Tristão (2003), "portanto, os critérios de repartição podem ser diferentes em cada Estado da Federação". A exemplo cita o estado de São Paulo, pontuando que: 
Valor adicionado, com peso de 76\%: média da relação percentual entre o valor adicionado de cada município e o valor adicionado de todos os municípios do Estado, nos dois exercícios anteriores ao da apuração;

População, com peso de 13\%: relação percentual entre a população de cada município e a população de todos os municípios do Estado, de acordo com o último recenseamento demográfico geral realizado pela Fundação Instituto Brasileiro de Geografia e Estatística (IBGE);

Receita tributária própria, com peso de 5\%: relação percentual entre o valor da receita tributária própria de cada município e a soma da receita tributária própria de todos os municípios do Estado;

Componente percentual fixo, com peso de $2 \%$ : o montante relativo a esse percentual é dividido igualmente pelo número de municípios do Estado;

Área cultivada, com peso de 3\%: percentual entre a área cultivada de cada município, no ano anterior ao da apuração, e a área cultivada total do Estado;

Área ocupada para geração de energia elétrica, com peso $0,5 \%$ : relação entre a área dos reservatórios de água destinados à geração de energia elétrica e a área total, no Estado, desses reservatórios, existente no exercício anterior;

Área de proteção ambiental, com peso 0,5\%: ponderado tendo em conta, principalmente, o total das áreas sob proteção ambiental existentes no município em relação ao total de áreas sob proteção ambiental existentes no Estado (TRISTÃO, 2003, p. 172).

Pode-se ser observado que existe uma certa predominância valor adicionado no índice de participação dos municípios na Quota-parte do ICMS. Objetiva-se então promover a volta do produto da arrecadação ao município em que é feito o movimento econômico e arrecadados impostos correspondentes.

Como problema, pode-se observar de acordo com Silva (1994), o valor pôde-se evoluir, quando se adicionado aos municípios que acompanham os procedimentos de industrialização e desenvolvimento. Todos estes que apresentam aumento econômico começam a conseguir maior valor e passam a crescer o índice de participação. 
Provém ainda destacar, de acordo com Massardi (2014), que a partir do aumento de incidência do ICMS, agrupados aos antigos impostos relacionados à energia elétrica, transportes interestaduais, combustíveis e minerais, os estados passaram a levar em conta as entradas e saídas desses materiais, elevando os valores adicionais para alguns municípios. Com a nova sistemática do ICMS, alguns municípios começaram a ser beneficiados. Têm-se como exemplo, o município de São Sebastião - SP, que mostra em sua área um porto de embarque e armazenagem de petróleo e derivados.

A finalidade do ICMS é a arrecadação de tributos sobre operações relativas à circulação de mercadorias e sobre prestações de serviços de transporte interestadual e intermunicipal, mesmo que essas operações sejam iniciadas no exterior. A Magna Carta pode permitir apenas que seja seletivo, decorrente da essencialidade dos serviços e mercadorias.

Com isso, a nova sistemática do ICMS objetiva diminuir a dificuldade do sistema tributário brasileiro. A fim de conseguir mais investimentos para o brasil e amenizar a guerra fiscal entre os estados para conseguir instalar as empresas em seus devidos territórios.

Logo podemos perceber que a nova sistemática é de fundamental importância para todos, pois qualificar os consumidores, contribuintes tais como a população em geral sobre os avanços e incrementos a serem conquistados com a nova proposta, diminui a disputa desenfreada causada pela guerra. Consequentemente, nota-se com mais facilidade os potenciais de investimentos proporcionados pela nova regra do recolhimento do tributo.

\section{CONSIDERAÇÕES FINAIS}

O Brasil é um país que adota o modelo de estado federativo, em que o ICMS é de competência dos estados e do Distrito Federal. Assim, tornou-se difícil o entendimento e aplicação do ICMS, uma vez que cada estado tem autonomia para adoção de suas próprias alíquotas interestaduais. 
Isso fez com que aumentasse a disputa entre lugares, pois os estados menos favorecidos criaram programas de incentivos fiscais, muitas vezes até inconstitucional, em busca de suprir a deficiência causada pela maior concentração de empresas, investimentos e das indústrias em algumas poucas regiões do país. Assim sendo, retomando a questão norteadora: como a nova forma de tributar o ICMS pode contribuir para minimizar as divergências existentes na economia entre os estados? Concluímos que a nova sistemática de recolhimento do ICMS ameniza essa disputa. Através do princípio da tributação no destino. Ou seja, a receita será recolhida e arrecadada pela unidade da federação ao qual o produto se destina e não onde é produzida.

Logo, a nova sistemática de recolhimento do ICMS para os estados brasileiros é importantíssima, pois se destaca o potencial de incremento na arrecadação dos estados menos favorecidos, tornando justas as operações entre estes. Assim, a promoção da justiça tributária contribui para o fim da disputa.

Entende-se que avanços serão conquistados, pois o incremento na arrecadação dos estados, eleva os investimentos em educação, saúde, segurança, e ademais projetos de ordem social que perdiam investimentos. Minimizando assim, a disputa entre estados a famosa "Guerra Fiscal".

Conclui-se que muito há a ser debatido sobre o assunto e que as mudanças amenizaram essa disputa. Logo para reduzir ainda mais e buscar o fim definitivo a guerra fiscal no Brasil, urge como elemento principal maior investimentos públicos, além de esforços em melhorar as políticas públicas de desenvolvimentos entre os estados, buscando assim a justiça tributária e a promoção de dias melhores a todos.

A leitura do presente artigo é indicada à comunidade acadêmica do curso de Bacharelado em Ciências Contábeis, Administração, bem como profissionais das áreas, contribuindo assim para diversas pesquisas nesta temática, além disso, destina-se a toda a sociedade que se interessa pelo conhecimento do novo método de recolhimento do ICMS. 


\section{REFERÊNCIAS}

ARBIX, G. Guerra fiscal e competição intermunicipal por novos investimentos no setor automotivo brasileiro. Dados, v. 43, p. 5-43, 2000.

ASSOLARI, R. A. Nova Sistemática de Recolhimento do ICMS Interestadual. Paraná. Portal Tributário. 2015.

BRASIL. Código Tributário Nacional. São Paulo: Saraiva, 2001.

. Lei Complementar n 86, de 13 de Setembro de 1996.

. Lei Complementar n 116, de 31 de julho de 2003.

. Lei Municipal n²65, de 25 de novembro de 2005.

. Lei $\mathbf{n}^{\circ}$ 4320, de 17 de março de 1964. Disponível em: >. Acesso em 03 de abril de 2012.

Emenda Constitucional ํo 87/ 2015. Disponível em: http://www.planalto.gov.br/ccivil_03/Constituicao/Emendas/Emc/emc87.htm.

. Constituição (1988). Constituição da República Federativa do Brasil. Brasília DF: Senado, 1988.

. Congresso Nacional. Lei Complementar n. 87, de 13/09/1996. Brasília: Diário Oficial da União, de 16 set. 1996

DATA INFO (Brasil). ICMS/MG - DIFAL - Operações interestaduais promovidas para operações com Minas Gerais. 2. ed. Minas Gerais: Copyright, 2016. Disponível em: https://www.datainfo.inf.br/subsites/eme4_boletec/Boletec\%20\%20Eme4\%20Corporativo\%C2\%A9.html?ICMSMGDIFALOperacoesinterestadua.ht ml. Acesso em: 20 maio 2021.

FEDERAL, Receita. Ministério da Fazenda. Base de Dados, 2017. 
GAEL, I. Alteração na venda a consumidor final de outro estado: saiba como a nova lei do ICMS impacta no processo de venda de uma empresa optante pelo simples nacional. Rio Grande do Sul: Cepebel Escritório Contábil Ltda, 19 jan. 2016. Disponível em: http://www.cepebel.com.br/novo/alteracao-na-venda-a-consumidorfinal-de-outro-estado/. Acesso em: 18 fev. 2021.

ICMS - DIFERENCIAL DE ALÍQUOTAS - CONSUMIDOR FINAL NÃO CONTRIBUINTE - SEGURADORA - ORIENTAÇÃO DA RECEITA ESTADUAL MEF31609 - LEST MG. Minas Gerais, 2017. Disponível em: http://www.informef.com.br/paginas/mef31609.htm. Acesso em: 7 abr. 2021.

MARI, C. L. et al. Sociedade do conhecimento e educação superior na década de 1990: Banco Mundial e a produção do desejo irrealizável de Midas. 2006.

MARCONI, M. A. ; LAKATOS, E. M. Fundamentos de metodologia cientifica. 7. reimpr. São Paulo: Atlas, 2009.

MASSARDI, W. O.; ABRANTES, L. A. Classificação dos municípios mineiros em relação à composição de suas receitas. Revista de Gestão, Finanças e Contabilidade, v. 4, n. 1, p. 144-161, 2014.

MENDES, K. D. S.; SILVEIRA, R. C. C. P., GALVÃO, C. M. Revisão Integrativa: método de pesquisa para a incorporação de evidências na saúde e na enfermagem. Texto Contexto Enferm, Florianópolis, n. 17, v. 4, p. 758-764, 2008.

PAES, N. L.; SIQUEIRA, M. L. Desenvolvimento regional e federalismo fiscal no Brasil: em busca da igualdade na distribuição de receitas. Economia Aplicada, v. 12, n. 4, p. 707-742, 2008.

A Implantação do Princípio do Destino na Cobrança do ICMS e suas Implicações Dinâmicas sobre os Estados. Revista Brasileira de Economia, v. 63, p. 233-248, 2009. 
PENA, R. F. A. Guerra Fiscal no Brasil. Brasil Escola. Disponível em: https://brasilescola.uol.com.br/brasil/guerra-fiscal-no-brasil.htm. Acesso em 09 de junho de 2021.

PORTAL TRIBUTÁRIO. ICMS - Vendas destinadas a consumidor final. In: ICMS Vendas destinadas a consumidor final. [S. I.], 2015. Disponível em: https://portaltributario.com.br/artigos/vendasaconsumidor.htm. Acesso em: 10 maio 2021.

RECOLHIMENTO DO DIFERENCIAL DE ALÍQUOTA. S.I.: Contabilidade Brasil, 2 jul. 2021. Disponível em: https://www.contabilidadenobrasil.com.br/convenio-icms-152de-2015/. Acesso em: 13 abr. 2021

SILVA, M. N. P. "ICMS"; Brasil Escola. Disponível em $<$ http://brasilescola.uol.com.br/economia/icms.htm>. Acesso em 13 de agosto de 2016.

SERRA, J. Federalismo fiscal à brasileira: algumas reflexões. 1999.

TRISTÃO, J. A. M. , A Administração Tributária dos Municípios Brasileiros: uma avaliação do desempenho da arrecadação. São Paulo: EAESP/FGV, 2003. 172 p.

YAMAO, C. A História do Imposto Sobre Circulação de Mercadorias-do IVM ao ICMS. Revista Juridica, v. 3, n. 36, p. 40-53, 2014.

ZANOCCHI, V. H. C. S. ICMS e regime tributário das micro e pequenas empresas: uma análise da constitucionalidade da cláusula 9ª do convênio 93/2015 do conselho nacional de política fazendária. 2016.

Enviado: Junho, 2021.

Aprovado: Dezembro, 2021. 